\title{
Isolation of Staphylococcus aureus from Raw Cattle Milk and their Drug Resistance Pattern
}

\author{
R.K. Patel ${ }^{1}$, R. Kumar ${ }^{1 *}$, C.V. Savalia ${ }^{1}$ and N.G. Patel ${ }^{2}$ \\ ${ }^{1}$ Department of Veterinary Public Health and Epidemiology, College of Veterinary science \& \\ Animal Husbandry, Navsari Agricultural University, Navsari-396 450, Gujarat, India \\ ${ }^{2}$ Department of Livestock Products Technology, College of Veterinary science \& Animal \\ Husbandry, Navsari Agricultural University, Navsari-396 450, Gujarat, India \\ *Corresponding author
}

\section{Keywords \\ Antibiotics, Food, \\ Raw milk, $S$. \\ aureus, Food \\ poisoning}

Article Info

Accepted:

10 January 2018

Available Online:

10 February 2018

\section{A B S T R A C T}

Staphylococcus aureus is one of the important human pathogens involved in food related diseases and common community associated infections. This organism proliferates in food and causes food-borne illnesses. Milk serves as an ideal medium for growth of many microorganisms including Staphylococcus aureus. A total of 118 raw cattle milk samples were collected under aseptic precautions from different places of Navsari district of south Gujarat, processed under standard bacteriological techniques. The Baird Parker Agar was sued as selective medium for isolation. The presumptive isolates were identified on the basis of their morphological, cultural and biochemical characteristics. The sensitivity pattern of $S$. aureus with different antimicrobial agents was evaluated by disk diffusion method. Analysis of result revealed 12 isolates $(10.16 \%)$ of $S$. aureus from 118 milk samples. The $S$. aureus isolates showed cent percent sensitivity towards Amikacin and Gentamicin, followed in reducing levels by Gatifloxacin (91.66 \%), Ciprofloxacin (91.66 $\%), 75 \%$ each, of Streptomycin and Kanamycin; Ampicillin (66.66 \%) and Cephalexin $(41.66 \%)$. The pattern clearly indicated overall high percent resistance to Cephalexin (58.33\%), followed by Ampicillin (33.33\%), Methicillin (25.00\%), Kanamycin (16.66 \%) and Gatifloxacin $(8.33 \%)$, Ciprofloxacin $(8.33 \%)$. The isolates showed intermediate sensitivity towards Streptomycin $(25.00 \%)$ and Kanamycin $(8.33 \%)$. Findings of the study suggested judicious use of antimicrobial therapy in milking animals.

\section{Introduction}

Milk is a major component in the human diet of vegetarian class, but it also serves as very good medium for the growth of many microorganisms including pathogenic bacteria (Ruegg, 2003). Milk is a highly valuable food, but raw milk contains and favors growth of many microorganisms. Milk and its derivates are considered as a major source of Staphylococcus aureus infection in man (Jahan et al., 2015). Milk can act as a vehicle for transmitting the $S$. aureus from animal to cause the severe foodborne intoxication in human. It has been recorded that S. aureus causes the subclinical mastitis and contaminate the udder and milk; acting as the main source of contaminants. Contaminated 
milking equipment's and the milker's hands also may be the source of infection (Capurro et al., 1999).

Staphylococcus aureus grow as smooth, circular, convex colonies of $0.5-1.5 \mu \mathrm{m}$ in diameter with lustrous growth. The colony pigmentation may vary from grey, grey-white, grey- white with yellowish to orange shades and in blood agar typical $\beta$-hemolysis may be produced; depending on the growth condition (Jahan et al., 2015).

Microscopic morphology reveals irregular bunches of grapes like clusters of cells. $S$. aureus is Gram +ve, aerobic and facultative anaerobic, oxidase-negative, catalase-positive, non-motile, fermentative, and non-spore forming cocci (Carter et al., 1994). S aureus may be pathogenic or non-pathogenic and the pathogenic strains are usually coagulasepositive and cause disease in their hosts (Jahan et al., 2015). Staphylococcus aureus is a versatile pathogen of humans and animals causes a wide variety of diseases from mild skin infection to more severe diseases such as pneumonia and septicaemia (Lowy, 1998).

Antimicrobial resistance is a main public health worry worldwide. The expansion of resistance both in human and animal bacterial pathogens has been allied with the widespread remedial use of antimicrobials or with their administration as growth promoters in animals (McNamara, 2000). Several authors observed that administration of antibiotics to food producing animals for remedial purposes or as growth promoters may be a primary factor in selecting for antimicrobial-resistant bacteria (Barber et al., 2003).

Thus, the objective of this study was to isolate Staphylococcus aureus from raw cattle milk and evaluation of thedrug resistance pattern of $S$. aureus isolates using different antimicrobial agents.

\section{Materials and Methods}

\section{Sample collection}

A total of 118 raw milk samples (approximately $10 \mathrm{~mL}$ from each) of apparently healthy cow were collected from different places of Navsari district of south Gujarat by using sterile test tube. The samples were collected from March 2016 to June 2016 and investigation was carried out following collection. The laboratory works were accomplished in the laboratories of the Department of Veterinary Public Health And Epidemiology, Navsari Agricultural University, Navsari.

\section{Isolation and identification of $S$. aureus}

The selective medium used for isolation of $S$. aureus was Baird Parker Agar (BPA) (HiMedia). A $0.1 \mathrm{ml}$ of each 10 fold diluted sample was spread on BP agar using a sterile pipette and sterile spreader and incubated for 24-48 hours at $37{ }^{\circ} \mathrm{C}$. The organisms were isolated and identified as methods described by Cowan and Steel (1975), Singh and Prakash (2008). and Quinn et al., (1994). Characteristic appearance of jet black colonies surrounded by a halo zone were considered to be presumptive $S$. aureus. The pure cultures were streaked on Nutrient agar or Mannitol salt agar and incubated for 24 hours at $37{ }^{\circ} \mathrm{C}$ and were further characterized by biochemical tests.

\section{Morphological characteristics}

The smear was prepared from the isolated culture on clean grease free microscopic glass slide and stained with Gram's method of staining. The stained smear was observed under microscope. Smear revealed Gram positive, spherical cells arranged in irregular clusters resembling to bunch of grapes. 


\section{Biochemical examination}

Biochemical tests were performed to confirm $S$. aureus using Catalase test, Coagulase test, motility test, DNase test, haemolysin test and D-mannitol fermentation and maltose fermentation.

\section{Antibiotic susceptibility assay}

All the $S$. aureus isolates were subjected to antibiotic sensitivity testing by standard disc diffusion method on Muller-Hinton agar (Himedia) according to the National Committee of Clinical Laboratory Standards (NCCLS) recommendations. Drug resistance patternof the isolates to Amikacin $(10 \mu \mathrm{g})$ Ampicillin $(25 \mu \mathrm{g})$, Cephalexine $(30 \mu \mathrm{g})$, Ciprofloxacin $(30 \mu \mathrm{g})$, Gatifloxacin $(5 \mu \mathrm{g})$, Gentamicin $(50 \mu \mathrm{g})$, Kanamycine $(30 \mu \mathrm{g})$, Methicillin $(5 \mu \mathrm{g})$, Streptomycin $(10 \mu \mathrm{g})$ were determined. Isolates were divided into three groups based on the zone of inhibition produced by the antibiotic disc; susceptible, intermediately susceptible and resistant according to the National Committee of Clinical Laboratory Standards (NCCLS) guideline; Performance Standards for Antimicrobial Susceptibility Testing (NCCLS, 2014).

\section{Results and Discussion}

Out of 118 raw milk samples processed, 12 $(10.16 \%)$ samples yielded the growth of $S$. aureus, identified based on cultural and biochemical characteristics (viz., Gramstained smears of the pure cultures exhibited clusters of Gram-positive cocci, positive for catalase and coagulase test and results at par with other biochemical tests). Result of antibiotic sensitivity test revealed that all the isolates were sensitive to Amikacin and Gentamicin, followed in reducing levels of sensitivity by Gatifloxacin (91.66\%), Ciprofloxacin (91.66\%), 75 per cent each of
Streptomycin, Kanamycin and Methicillin; Ampicillin (66.66 \%) and Cephalexin (41.66 $\%)$. The pattern indicated varying levels of resistance to Cephalexin (58.33\%), Ampicillin (33.33\%), Methicillin $(25.00 \%)$, Kanamycin $(16.66 \%)$ and 8.33 per cent each of Gatifloxacin and Ciprofloxacin. The isolates showed intermediate sensitivity towards Streptomycin (25.00 \%) and Kanamycin $(8.33 \%)$.

In this study we describe the isolation, identification and antibiotic susceptibility characterization of $S$. aureus from raw cattle milk obtained from different places of Navsari district of south Gujarat. The results of present prevalence study in Navsari district of south Gujarat region of India and other author's results from various parts of the world are differing vastly. Even from different regions of India also the prevalence rates were differing. However, results of study results at Navsari district region showed prevalence of 10.16 per cent, which were high compared to other studies conducted by Thaker et al., (2013), who reported $6.25 \%$ in Anand (Gujarat) region of India and lower than Kumar and Prasad (2010). Reported 26\% prevalence in milk samples collected from local vendors of Pantnagar, India. Sarkar, et al., (2014) documented 74.5\% (149/200) of the milk samples were positive for $S$. aureus from the Karnal, North India, and Lingathurai and Vellathurai (2011) reported $61.7 \%$ of prevalence of $S$. aureus from 60 raw milk samples from Madurai region of South India; it is very higher than our study.

Results obtained from this study were more or less when compared with the prevalence rates that reported by various authors in different tropical and temperate countries. Prevalence rate from morocco, Palestine and Bangladesh reported by Bendahon et al., (2008), Farhan and Salk (2007) and Jahan et al., (2015) as $40 \%, 36.9 \%$ and $25.53 \%$ respectively, which 
were higher to our study. However, similar prevalence has been previously reported by Fagundes et al., (2010) (10.8\%) from Sao Paulo state, Brazil, Ayano et al., (2013) (13.8\%) from Holeta, Ethiopia. From all these study results of above mentioned indicates prevalence of $S$. aureus is varied from place to place and regions to regions around the world and it highlights that hygienic practice of milking and selling influence the prevalence of $S$. aureus in milk.

According to the obtained results of antibiotic sensitivity tests on the $S$. aureus isolates from raw milk was varied from previous study conducted by Thaker et al., (2013). In this study, the isolates were sensitive to Gentamicin (100\%), Ciprofloxacin (91.66\%), Streptomycin (75\%), Methicillin (75\%); Ampicillin (66.66 \%) and Cephalexin (41.66 $\%)$.whereas in Thaker et al., (2013) study; it was $90(\%), 80(\%), 60(\%), 100(\%), 60(\%)$ and $100(\%)$, respectively. In this study varying levels of resistance to Cephalexin (58.33\%), Ampicillin (33.33\%), Methicillin (25.00\%), and 8.33 per cent of Ciprofloxacin. whereas in Thaker et al., (2013) study; only 40 per cent resistance to ampicillin while zero per cent resistance reported to Cephalexin, Methicillin, and Ciprofloxacin antimicrobial agent. This difference in the results of various studies indicates antibiotic resistant pattern of $S$. aureus changing. By means of different mechanisms, S. aureus developing resistant to different antibiotics day by day. Isolation of antibiotic resistant $S$. aureus from milk samples against these drugs poses a major challenge in human medicine because these drugs are commonly used in the treatment of human.

From the current study, it is noted that intermediate sensitivity towards Streptomycin (25.00 \%) against S. aureus. \%).while in Thaker et al., (2013) study; it was 30 per cent, respectively. if the necessary action not taken against indiscriminate use of antibiotics, prevalence of antibiotic resistant $S$. aureus may increase further, it may lead to serious health hazards to humans.

Findings of the study suggested judicious use of antibiotics/anti-microbial agents for prophylactic as well as other respectively therapeutic purpose could be the reasons for increased highest antimicrobial resistance of $S$. aureus. A relatively high number of strains are also resistant to the antibiotics commonly used in the therapeutic protocols of many human and animal infections.

\section{References}

Ayano, A.A., Hiriko, F., Simyalew, A.M. and Yohannes, A. 2013. Prevalence of subclinical mastitis in lactating cows in selected commercial dairy farms of Holeta district. J. Vet. Med. Anim. Health, 5(3): 67-72.

Barber, D. A., Miller, G. Y. and McNamara, P. E. 2003. Models of antimicrobial resistance and foodborne illness: examining assumptions and practical applications, J. Food Prot., 66:700-709.

Bendahon, A., Lebbadi, M., Ennanei, L., Essadqui, F.Z. and Abdin, M. 2008. Characterization of Staphylococcus species isolation from raw milk and milk products (ilben and jben) in North Marocco. J. Infect. Dev. Ctries., 2: 218225.

Capurro, A., Concha, C., Nilsson, L. and Ostensson, K. 1999. Identification of coagulase positive Staphylococci isolatedfrom bovine milk. Acta Vet. Scand., 40: 315-321.

Carter, G. R., Chengappa, M. M. and Roberts, A. W. 1994. Staphylococcus. In: Essentials of Veterinary Microbiology. 5th Ed, Williams Wilkins, Philadelphia, USA, pp: 115-120.

Cowan, S. T. and Steel, K. J. 1975. Cowan 
and Steel's manual for the identification of medical bacteria. Cambridge University Press, Cambridge.

Fagundes, H., Barchesi, L., Filho, A. N., Ferreira, L.M. and Oliveira, C.A.F. 2010. Occurrence of Staphylococcus aureusin raw milk produced in dairy farms in São Paulo state, Brazil. Braz. J. Microbiol., 41(2): 376-380.

Farhan, M. and Salk, S. 2007. Evaluation of bacteriological contamination in raw (unprocessed) milk sold in different regions of Lahore (Pakistan). J. Agric. Soc. Sci., 3: 1813-2235.

Jahan, M., Rahman, M., Parvej, M. S., Chowdhury, S. M. Z. H., Haque, M. E., Talukder, M. A. K. and Ahmed, S. 2015. Isolation and characterization of Staphylococcus aureus from raw cow milk in Bangladesh. J. Adv. Vet. Anim. Res., 2(1): 49-55.

Kumar, R. and Prasad, A. 2010. Detection of E. coli and Staphylococcus in milk and milk products in and around Pantnagar. Veterinary world. 3 (11):495-496.

Lingathurai, S. and Vellathurai, P. 2011. Bacteriological quality and safety of raw cow milk in Madurai, South India. Webmed. Cent. Microbiol, 1: 1-10.

Lowy, F. D. 1998. Staphylococcus aureus infection. N. Engl. J. Med., 339: 520532.

McNamara, P. J., Milligan-Monroe, K. C., Khalili, S., Proctor, R. A. 2000. Identification, cloning, and initial characterization of rot, a locus encoding a regulator of virulence factor expression in Staphylococcus aureus. J. Bacteriol., 182:3197-3203.

National Committee for Clinical Laboratory Standards 2014. Performance Standards for Antimicrobial Susceptibility Testing; Twenty-Fourth

Informational Supplement., approved standard M100S24. Wayne, PA.

Quinn P. J., Carter M. E., Markey B. K. and Carter G. R., 1994. Clinical veterinary microbiology. Wolfe Publishing, London, England.

Ruegg P. L. 2003. Practical food safety interventions for dairy production. $J$. Dairy Sci., 86: E1-E9.

Sarkar, P., Mohanta, D. and Debnath, C. 2014. Staphylococcus aureus in dairy animals and farm workers in a closed herd in Karnal, North India: Assessment of prevalence rate and COA variations. Int. J. Innov. Res. Sci. Eng. Technol., 3(4): 10962-10972.

Singh, P. and Prakash, A. 2008. Isolation of Escherichia coli, Staphylococcus aureus and Listeria monocytogenes from milk products sold under market conditions at Agra Region. Acta Agri. Slov. 92: 8388.

Thaker, H.C., Brahmbhatt, M.N. and Nayak, J.B. 2013. Isolation and identification of Staphylococcus aureus from milk and milk products and their drug resistance patterns in Anand, Gujarat. Vet. World, 6(1): 10-13.

\section{How to cite this article:}

Patel, R.K., R. Kumar, C.V. Savalia and Patel, N.G. 2018. Isolation of Staphylococcus aureus from Raw Cattle Milk and Their Drug Resistance Pattern. Int.J.Curr.Microbiol.App.Sci. 7(02): 836-840. doi: https://doi.org/10.20546/ijcmas.2018.702.105 